\title{
USER ANALYSIS FOR E-INCLUSION IN A BLENDED LEARNING COURSE DELIVERY CONTEXT
}

\author{
Ieva Vitolina \\ Atis Kapenieks \\ Riga Technical University Distance Education Study Centre
}

\begin{abstract}
The authors' purpose was to analyse users of the blended e-learning course "Improvement of ICT skills" in context of e-inclusion and determine indicators for e-inclusion facilitation. We applied a practical use probability model to perform the analysis that identified the following factors: the degree to which the instructor was willing and able to share knowledge; the degree to which the students were interested and had the capacity to learn; and the degree to which the sponsoring organization supported and promoted learning. The study was based on evaluating a group of five hundred vocational teachers who were the learners. Our results indicated that the quality of e-learning materials and environment, instructor's support, student willingness and ability to learn were attributes that could impact learning carry-over and promoted e-inclusion.
\end{abstract}

Keywords: E-inclusion, e-learning, digital skills, digital skills gap, usage gap

\section{Introduction}

This study aims to address the e-inclusion problem that was outlined in the EU Digital Agenda 2020 that relates to the inclusion of as many individuals as possible to enjoy the benefits of information and communication technology (ICT) (Digital Agenda, 2010). This study refers to the delay that the e-inclusion process has encountered. The progress report of the EU Digital Agenda states that there still exists a sharp divide in digital use and competence in Europe that may be identified between nations as well as along socio-economic lines although improvements are being made (European Commission, 2011). Lack of digital skills and advanced usage of digital skills are particularly important issue in a number of countries.

Nowadays the digital divide goes beyond the issue of access to technology. Focus has shifted from access to ICT to digital skills and the meaningful use of ICT (Hargittai, 2000; McLean, 2006; Zhao, \& Elesh, 2006). There is a gap between knowing to do and practical usage of digital skills. Learning a new skills and using it are two separate steps (Lerchner, Camera, \& Richmond, 2007). The 2010 OECD report stated that a second digital divide separates those with the competencies and skills that benefits from computer use from those without these advantages (OECD, 2010).

This study addresses the issues of the second digital divide. There is little research to determine how to prevent the second digital divide (Deursen, \& Dijk, 2010). This study contributes to research of the factors influencing meaningful ICT use in blended learning context. 


\section{Knowing / Doing gap and knowledge flows in the e-inclusion model}

We used the theory of knowledge management to conceptualize the e-inclusion process in the context of the meaningful use of digital skills. Knowledge management theory uses terms "knowing" and "doing" to address issue of turning knowledge about something into action consistent with that knowledge (Pfeffer, \& Sutton, 1999). In the context of our study, "knowing" means digital skills or ability to apply knowledge to complete tasks related ICT; while "doing" means the meaningful use of digital skills for business or private needs. Doing or meaningful ICT use indicates that the person is e-included.

According to Nissen (2006) knowing-doing gap can stem from problems with knowledge flows. Nissen (2006) stated that for knowledge to flow at the individual level, the instructor or expert must be willing and able to share; the student must be willing and able to learn; and the organization must be willing and able to help them do so.

We proposed a model to analyze practical use probability for the skills learned in a blended e-learning course by identifying the following factors:

(F1) the degree to which instructor was willing and able to share knowledge;

(F2) the degree to which the students were willing to learn; and the learning capacity of the students;

(F3) the degree to which the organization supported learning development; the degree in which the organization promoted learning.

\section{Factor 1: Instructor's willingness and ability to share knowledge}

The instructor's willingness to share knowledge we understand as support given to students to facilitate learners' needs.

We limited our research to the blended e-learning process. If students use an elearning environment, then the role of instructor in sharing knowledge changes as well. Students learn not only in classroom seminars but also anywhere where is an Internet connection. Knowledge acquisition depends upon the quality of the content, i.e. learning materials, and the usability of the e-learning environment for convenient use of content and communication with the instructor. In our model we proposed that knowledge flow is related to quality of learning course materials and usability of e-learning environment.

\section{Factor 2: Student's willingness and ability to learn}

There are no fully understood research methods for measuring a student's willingness to learn. We proposed that the willingness to learn is expressed by a student's show of interest. Interests have been identified as an important motivational construct that influences achievement in learning (Abrantes, Seabra, \& Lages, 2007; Subramaniam, 2009). According to John Dewey (1913) learning results depend on a student's interests. In our model we determined student willingness to learn digital skills by four types of interests: social, intellectual, professional, and private.

Students' ability to learn we described as the students' previous experience, 
which was reflected by their knowledge level. A student previous experience plays an important role in the model. In constructionist theory, each student constructs new knowledge from his experiences (Powell, \& Kalina, 2009; Vedins, 2011). During the learning process the knowledge level of student can increase. We proposed that percentage increases in the students' knowledge level as a result of the course indicated the students' ability to learn.

\section{Factor 3: Organizational support and promotion of learning development}

As indicated above, we limited our study the teaching and learning of the ecourse. We expected that the interested organization had secured an e-learning environment that was equally accessible to all interested students; that the organization was impartial and actively supported all students without bias; and that all students had an equal opportunity to complete the e-learning course for digital skills improvement.

\section{The Scope of the study and the research questions addressed}

We limited our study to the Factor 1 and Factor 2. We felt they were the most significant factors for our study because we were interested in predicting vocational teachers continued usage of digital skills learned in the e-course after the course was finished. Our purpose was to use the instructor's willingness, quality level of learning materials, usability of e-learning environment and student's willingness and ability to learn to obtain a better comprehension of the students' which practically use digital skills after completing the blended learning course "Improvement of ICT skills".

We felt the following research questions would give us the clearest indicators for this outcome:

(RQ1) Does the student's evaluation of instructor's willingness to share knowledge differ for students which use practically digital skills?

(RQ2) Does the student's evaluation of quality of e-learning materials differ for students which use practically digital skills?

(RQ3) Does student's satisfaction with the e-learning environment differ for students which use practically digital skills?

(RQ4) Does student's willingness to learn differ for students which use practically digital skills?

(RQ5) Does student's ability to learn differ for students which use practically digital skills?

\section{Method}

\section{Participants}

The participants included 500 students. They were teachers of vocational schools in Latvia. The sample covered $80 \%$ of students in the blended e-learning course "Improvement of ICT skills".

Based on vocational teachers inquiry the blended e-learning course contained 
most important topics for teachers to develop digital competence (Ala-Mutka, 2011). The topics of the course related to the improvement of instrumental knowledge and skills for tool and media usage, advanced skills and knowledge for communications, information management, and continued learning and meaningful participation in a knowledge society. We analysed ten topics: Setup of peripherals, Image scanning, Web page design, PDF files, Computer security, MS Access, Video processing, E-learning materials, Social networks, and Email. Each topic included theoretical material in video and text format and tests for knowledge assessment. In addition, we assigned practical exercise to apply the knowledge gained (Roskelly, 2005).

\section{Measures}

We designed three types of questionnaires to assess different aspects of the practical use of digital skills. These questionnaires were piloted at the end of 2010 in the group of 12 vocational teachers and a final version were piloted at the end of 2010 with a group of twelve vocational teachers and upon the results a final version of the questionnaire was developed.

(I) The students completed the first questionnaire prior to entering the course.

(II) The next ten questionnaires were given at the end of each topic.

(III) The last questionnaire was at the end of the course.

These questionnaires contained 10-14 Likert-type scale (ranged from 1 strongly disagree to 5 - strongly agree) questions.

We used these questionnaires to assess student's willingness and ability to learn, their attitude to e-learning materials and their previous digital skills. Another questions related to prediction about learned digital skills usage for private or business needs. Three questions assessed the e-learning environment, and the last question related to evaluation of instructor willingness to share knowledge. Additionally, we designed a telephone questionnaire to obtain data about the practical usage of digital skills after completing the e-learning course. For each topic the students were classed in the following categories:

(a) Those that did not practically use the digital skills after completing the course. For example, if the student did not use social networks after the elearning course then the student indicated on the survey that he did not use the course topic Social networks.

(b) Those that used digital skills after completing the course but did not practically use those skills learned in the course. For example, student had skills before learning Social network topics such as how to create a Twitter account and how to use Twitter. During the course student learned how to create a Facebook account and how to use Facebook. If we observed that the student used Twitter but not Facebook (newly acquired skills) after the course, then the student indicated on the survey that he did not use newly acquired skills for this topic.

(c) Those that used newly acquired digital skills after completing the course For example, the student acquired Facebook skills in the course, but had not used it 
before. After completing course student used Facebook. Then he indicated on the survey that he used newly acquired skills.

The telephone survey was similarly piloted as questionnaires at the end of 2010 in the same group of 12 vocational teachers and a final version was developed.

Attributes. The are two attributes for knowledge flow analysis in context of 3course. The first attribute was instructor's willingness and ability to share knowledge during e-learning course for the improvement of digital skills. This was measured by three independent variables: (I) students' evaluation of instructor support in classroom seminars and in the e-learning environment; (II) student's evaluation of e-learning materials of course; (III) student's evaluation of e-learning environment. The second attribute was student's willingness and ability to learn. This was measured by two independent variables: (I) student's willingness to learn (by means of their interests to enter in e-course), (II) student's ability to learn (by means of increase of their knowledge level after ecourse). We also determined student's digital skill level before learning in accordance to Digital Agenda Scoreboard key indicators (European Commission, [2014]).

As criterion attributes we used (I) students' prediction of digital skills practical use (by means of the questionnaire), (II) observed use of digital skills (by means of the telephone surveys).

\section{Procedure}

Data collection. We collected the data from the students by means of questionnaires administered from January to April 2012. The questionnaires were administered in the course and could access through Moodle. Moreover, we conducted surveys by phone from March to May 2012 to determine to what extent practical usage of learned digital skills were applied four to twelve weeks after course.

Data analysis. The authors employed cluster analysis with WEKA software (Machine Learning Group at the University of Waikato, [2014]). We used EM (Expectation-Maximization) and KMeans as clustering algorithms (Wu, 2008). We analysed 916 records of students activities.

\section{Results}

Figure 1 presents comparisons of predicted and observed usage means in five point scale. The dark line is students' self-prediction about practical usage of learned skills. The actual score of predicted usage was from 3.3 to 4.4. The lowest score of predicted usage was for the Web page design topic. The highest score was for E-mail topics. The average score of predicted usage is quit high. It means that vocational teacher's after completing blended learning course "Improvement of ICT skills" are interested in practical use of learned skills for personal or professional purposes.

The second line in Figure 1 shows the average score of observed use of learned 
skills. The actual score of observed use was less than for predicted use - from 1.8 to 3.4. Web page design, MS Access topics have lowest scores for the observed usage. It is possible that these topics are more complicated for students and not required in their private life or business.

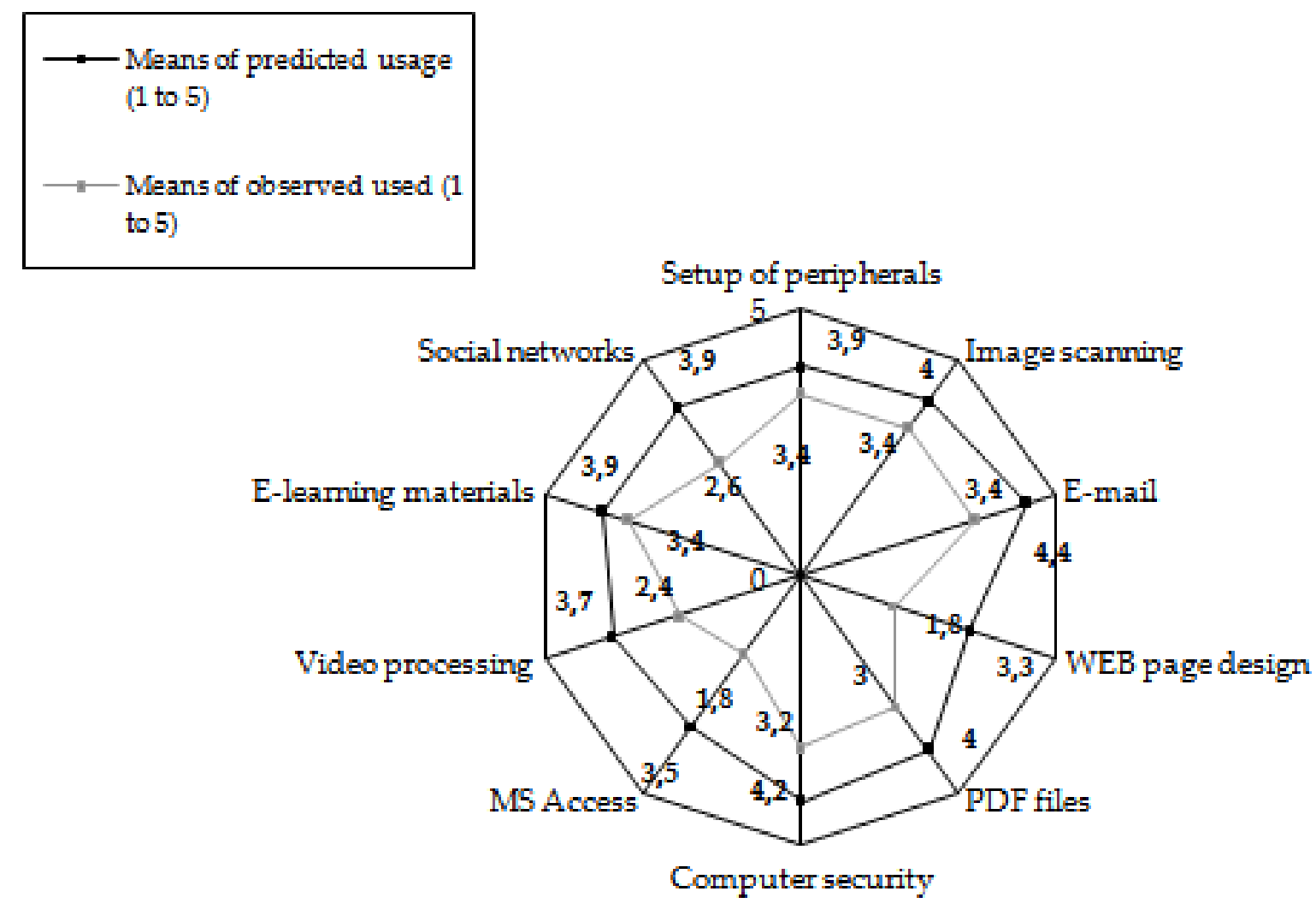

Figure 1 Means of predicted and observed use

We obtained that there are no significant correlations between predicted and observed usage.

Then we did clustering of students in context of observed usage of digital skills. We executed EM (Expectation-Maximization) algorithm in order to know the number of clusters with which the KMeans algorithm will be . The result obtained with Kmeans is presented in Table 1 and Figure 2. Each cluster is represented by its centroid, which means, the "average" of all its points. Table 1 consists of the absolute values of attributes but Figure 2 presents normalized values of the attributes.

There are four clusters of students in context of observed usage of digital skills: one cluster (Cluster 1) of students which don't use at all digital skills in their private or business live; one cluster (Cluster 2) of students which use digital skills at the same level as before e-course and two clusters (Cluster 3 and 4) of students which used new learned digital skills for their business or private live. 
Proceeding of the International Scientifical Conference May $23^{\text {th }}-24^{\text {th }}, 2014$

Volume II

\section{Attributes and student's clusters}

Table 1

\begin{tabular}{|c|c|c|c|c|c|}
\hline $\begin{array}{l}\text { Attribute } \\
\text { /Cluster }\end{array}$ & $\begin{array}{l}\text { Full data } \\
(916)\end{array}$ & $\begin{array}{l}1 \\
(298)\end{array}$ & $\begin{array}{l}2 \\
(334)\end{array}$ & $\begin{array}{l}3 \\
(147)\end{array}$ & $\begin{array}{l}4 \\
(137)\end{array}$ \\
\hline SWL (1 to 5) & 3.8 & 3.6 & 3.8 & 4.0 & 3.7 \\
\hline DS (0 to 1$)$ & 0.7 & 0.6 & 0.7 & 0.7 & 0.7 \\
\hline $\begin{array}{l}\text { SAL(1 to } \\
100 \%)\end{array}$ & 50.5 & 45.8 & 52.3 & 81.0 & 23.7 \\
\hline ELM (1 to 5) & 4.0 & 3.9 & 4.0 & 4.5 & 3.8 \\
\hline IWS (1 to 5) & 4.6 & 4.6 & 4.6 & 4.8 & 4.6 \\
\hline ELE (1 to 5) & 4.1 & 4.1 & 4.1 & 4.5 & 4.0 \\
\hline PU (1 to 5) & 4.0 & 3.5 & 4.1 & 4.6 & 3.9 \\
\hline $\mathrm{OU}$ & $\begin{array}{l}\text { Use on the } \\
\text { same level }\end{array}$ & Not use at all & $\begin{array}{l}\text { Use on the } \\
\text { same level }\end{array}$ & Use new skills & Use new skills \\
\hline
\end{tabular}

SWL

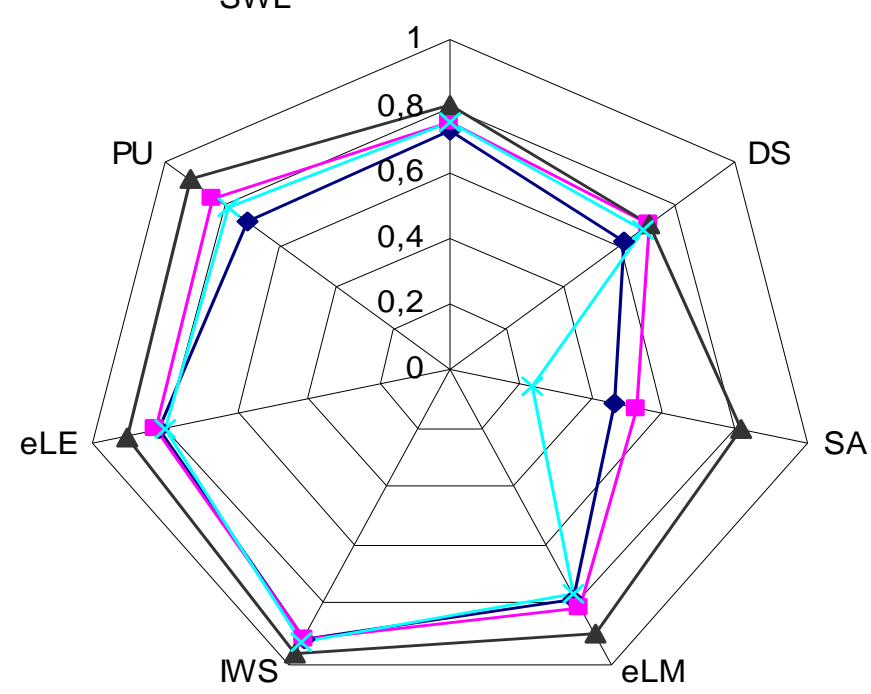

$\multimap$ Cluster 1: Not use

$\longrightarrow$ Cluster 2: Use practically on the same level

$\multimap$ Cluster 3: Use

practically new skills

- Cluster 4: Use

practically new skills

Figure 2 Clusters of students in context of observed usage

We observed that there are two clusters of students which used learned digital skills (Cluster 3 and 4). The values of cluster's attributes differ. Cluster 3 has the highest evaluations for all attributes: Student's willingness to learn (SWL) - 4.0, student's level of digital skills before learning (DS) -0.7 , student's ability to learn (SAL) - 81.0\%, e-learning material evaluation (eLM) - 4.5, instructor's willingness to share knowledge (IWS) - 4.8, e-learning environment evaluation (eLE) -4.5 and predicted use of learned digital skills (PU) - 4.6. Cluster 4 has lower values of attributes, especially for student's ability to learn - only $23.7 \%$. The cluster of students which not use at all digital skills after e-course 
completing has the lowest values of attributes (SWL - 3.6, DS - 0.6, SAL 45.8\%, ELM - 3.9, IWS - 4.6, ELE - 4.1, PU - 3.5). The exception is attribute: student ability to learn that is higher if compare it with cluster 4 .

The cluster of students which use digital skills on the same level has middle values if compare with other clusters $(\mathrm{SWL}-3.8$, DS - 0.7, SAL - 52.3\%, ELM - 4.0, IWS - 4.6, ELE - 4.1, PU - 4.1).

Results showed that students which do not use learned skills have lower values of predictions. For example prediction value is 3.5 for students which do not use digital skills. But value is 4.6 for students which use digital skills.

(RQ1) Does the student's evaluation of instructor's willingness to share knowledge differ for students which use practically digital skills?

We observed that instructor's willingness to share knowledge is the same or higher for students which use practically digital skills. The values of this attribute are 4.8. or 4.9. for students which use practically learned digital skills. Value is 4.8 for other student's clusters.

(RQ2) Does the student's evaluation of quality of e-learning materials differ for students which use practically digital skills?

We observed that students which practically use digital skills evaluate e-learning materials higher only in one of two clusters. Evaluation of e-learning materials is 4.5 for cluster 3 . This is the highest evaluation of all clusters. But cluster 4 has the value 3.8. This value is lower that evaluation of students which do not use digital skills or use at the same level as before e-course completing.

(RQ3) Does student's satisfaction with the e-learning environment differ for students which use practically digital skills?

We observed that students which practically use digital skills evaluate elearning environment higher (ELE - 4.5) than other students (ELE - 4.1).

(RQ4) Does student's willingness to learn differ for students which use practically digital skills?

We observed that students which practically use digital skills has different evaluations of willingness. For cluster 3 willingness have the higher value -4.0 if compare with other students. But another part of students which also use practically digital skills have not so high willingness to learn. Their evaluation is 3.7. It is lower than for students which use digital skills in the same level as before e-course completing.

(RQ5) Does student's ability to learn differ for students which use practically digital skills?

We observed that students which use practically digital skills have different ability to learn. Part of students has very high ability to learn $-81.1 \%$. But another part has quit low ability to learn - only $23.7 \%$. 


\section{Discussion and conclusions}

The purpose of the study was to investigate whether the instructor's support, elearning materials, the e-environment, student willingness and ability to learn are different for students which practically use newly learned digital skills and for other students.

First, we observed that the observed usage of student digital skills differs from their predictions. Also we observed that there is no correlation between predicted and observed usage of digital skills. It shows that highest prediction does not mean that students will use newly learned skills in their business or private live. This result presents that we must investigate real not predicted usage of digital skills to predict and facilitate digital skill usage and e-inclusion process. A possible reason for this outcome may be related to the fact that the evaluation was administrated too soon after the course was finished. To obtain more comprehensive and realistic data about practical use of learned digital skills it is necessary to prolong the period of vocational teachers' observation from three to six month after completing the training (Kirkpatrick, 1959).

Second, we clustered students to obtain a better comprehension of the students' which practically use digital skills after completing the blended learning course "Improvement of ICT skills". Our evidence indicates that the students' which practically use digital skills have the highest evaluations for all attributes: student's willingness to learn, student's level of digital skills before learning, student's ability to learn, e-learning material evaluation, instructor's willingness to share knowledge, e-learning environment evaluation and predicted use of learned digital skills. It means that when there is a high degree of satisfaction, the greater is the likelihood that obtained skills will be applied after the course finished.

Third, somewhat surprisingly and unexpected, we found that not always high satisfaction and ability to learn characterize the students which do not use digital skills. Among them are also students which used after course learned skills. We explain this situation in such way: students have high level of previous knowledge and it is reason why they have capacity to learn new skills and use these skills after e-course finishing.

Our findings indicate that instructor's willingness to share knowledge, satisfaction with e-learning environment and materials, student ability and willingness to learn, previous digital skills could be higher for students which use practically digital skills after e-course completing.

Our findings contribute to the current understanding of Nissen's knowledge management theory of knowledge flows as demonstrated by our blended elearning course for digital skills improvement. Our results match the finding of learning effectiveness studies that claim if learners felt better about the quality of the training (learning materials, environment), they acquired more knowledge and apply learned skills to their professional and practical lives (Sulčič, \& 
Lesjak, 2009; Yun-Tsan, Shui-Chuan, \& Hsiang-Ta, 2011).

A few methodological limitations should be noted. The sample used in the current study included only vocational teachers and the sample size for specific course topics was relatively small. Further study with larger samples is needed to examine the validity of the current findings.

We concluded that the that instructor's willingness to share knowledge, student's satisfaction with e-learning environment and materials, student's ability and willingness to learn, their previous digital skills are important attributes that characterize e-course users and their behavior in future according to practical usage of digital skills. The results confirmed the importance of designing quality e-learning materials and a virtual environment to reach a high number of e-excluded individuals. The implications of the research should encourage organizations and enterprises that are responsible for e-course design to take account of these factors. Obtained results are useful for e-learning managements and learning analytics tool development. Results indicate which attributes are necessary to analyse to promote practical usage of digital skills after completing e-course. Furthermore, the results indicate the need for further study of digital skills practical use possibility in context of designing tools for learning analytics.

The continued use of acquired skills enables individuals to become more active e-included participants both professionally and socially and furthers the goal of the EU e-inclusion policy. The study particularly addressed the issues concerned with the second digital divide of assisting vocational teachers to meet the challenges of the digital technology requirements of their professions. Moreover, we identified a practical use probability attributes that can be applied to future research.

\section{Acknowledgements}

This research has been supported by a grant from the European Regional Development Fund (ERFD/ERAF) project "New User behavioral interpretation algorithms to facilitate an efficient transfer of knowledge within an e-ecosystem (JAUZI)", Grant Agreement 2013/0071/2DP/2.1.1.1.0/13/APIA/VIAA/023.

\section{References}

1. Abrantes, J., Seabra, C., \& Lages, L. (2007). Pedagogical affect, student interest, and learning performance. Journal of Business Research, 60(9), 960-964.

2. Ala-Mutka, K. (2011). Mapping digital competence: Towards a conceptual understanding. Retrieved from ftp.jrc.es/EURdoc/JRC67075_TN.pdf

3. Dewey, J. (1913). Interest and effort in education. Retrieved from http://openlibrary.org/ books/OL7141097M/Interest_and_effort_in_education

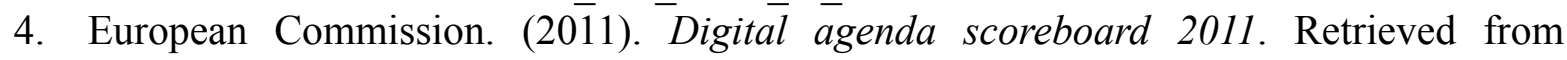
http://ec.europa.eu/information_society/digital-agenda/scoreboard/library/index_en.htm 
5. European Commission. (2014). Digital Agenda Scoreboard key indicators. Retrieved from http://digital-agenda-data.eu/datasets/digital_agenda_scoreboard_key_indicators/ indicators

6. A Digital Agenda for Europe. 2010. Retrieved from http://ec.europa.eu/ information_society

7. Deursen, A. J. A. M. v., \& Dijk, J. A. G. M. v. (2009). Improving digital skills for the use of online public information and services. Government Information Quarterly, 26, 333-340.

8. Deursen, A. J. A. M. v., \& Dijk, J. A. G. M. v. (2010). Internet skills and digital divide. New media \& society, 13(6), 893-911

9. Hargittai, E. (2000). Second-level digital divide: differences in people's online. Retrieved from Skillschnm.gmu.edu/digitalhistory/links/pdf/introduction/0.26c.pdf

10. Lerchner, A., Camera, G. L., \& Richmond B. (2007). Knowing without doing. Nature Neuroscience, 10(1). 15-17. Retrieved from http://ebookbrowse.com/2007-lerchner-etalknowing-without-doing-pdf-d78454237

11. Kirkpatrick, D. L. (1959). Techniques for evaluating training programs. Journal of American Society of Training Directors, 13(3), 21-26.

12. McLean, R. (2006). A tale of two e-citizens: a consideration of engagement in the esociety in two contexts. In Proceedings of the 14th European Conference on Information Systems, 2013-2016.

13. Nissen, M., E. (2006). Harnessing knowledge dynamics: Principled organizational knowing \& learning. London: IRM Press.

14. OECD. (2010). Are the new millennium learners making the grade? Retrieved from http://www.oecd.org/dataoecd/6/56/45000441.pdf

15. Oye, N., D., Salleh, M., M., \& Iahad, N. A. (2011). E-Learning barriers and solutions to knowledge management and transfer. Information Management \& Business Review, 3(6), 366-372.

16. Pfeffer, J., \& Sutton R., I. (1999). Knowing "what" to do is not enough: turning knowledge into action. California Management Review, 42(1), 83.-108.

17. Powell, K. C., \& Kalina, C. J. (2009). Cognitive and social constructivism: developing tools for an effective classroom. Education, 130(2), 241-250.

18. Roskelly, H. (2005). Still bridges to build: English education's pragmatics agenda. English Education, 37(4), 288-295.

19. Sulčič, V., \& Lesjak, D. (2009). E-learning and study effectiveness. Journal Of Computer Information Systems, 49(3), 40-47.

20. Subramaniam, P. R. (2009). Motivational effects of interest on student engagement and learning in physical education: A review. International Journal of Physical Education, 46(2), 11-19.

21. Vedins, I. (2011). Mācīšanas māksla. Rīga: Avots.

22. WEKA Machine Learning Group at the University of Waikato. 2014. Downloading and installing Weka, Retrieved from http://www.cs.waikato.ac.nz/ml/weka/ downloading.html

23. $\mathrm{Wu}, \mathrm{X}$. a.o. (2008). Top 10 algorithms in data mining, Knowl Inf Syst,14:1-37, Retrieved from http://www.cs.umd.edu/ samir/498/10Algorithms-08.pdf

24. Yun-Tsan, L., Shui-Chuan, C., \& Hsiang-Ta, C. (2011). The effect of Organizational commitment on employee reactions to educational training: an evaluation using the Kirkpatrick four-level model. International Journal Of Management, 28(3), 926-938. 
Proceeding of the International Scientifical Conference May $23^{\text {th }}-24^{\text {th }}, 2014$ Volume II

25. Zhao, S., \& Elesh, D. (2006). The second digital divide: unequal access to social capital in the online world. Retrieved from http://www.allacademic.com/ meta/p96480_index.html

M. Sci. Soc. Ieva Vitolina Riga Technical University Distance Education Study Centre, 12 Str. Azenes, Riga, LV 1048 Latvia Email: ieva.vitolina@rtu.lv

Dr. Phys. Atis Kapenieks Riga Technical University Distance Education Study Centre, 12 Str. Azenes, Riga, LV 1048 Latvia

Email: atis.kapenieks@rtu.lv 